\title{
UTJECAJ DODATKA SIRUTKE SJENAŽI LUCERNE NA SADRŽAJ MASNIH KISELINA U BURAGU KASTRIRANIH OVNOVA
}

\author{
Marina Vranić, K. Bošnjak, T. Mašek, Katarina Lovrić, \\ M. Papac, K. Krapinec, G. Kiš
}

\begin{abstract}
Sažetak
Cilj istraživanja bio je utvrditi utjecaj dodatka sirutke u prahu sjenaži lucerne (SL) na udio masnih kiselina u buragu kastriranih ovnova. U istraživanju su korištena 3 hranidbena tretmana: (i) $100 \%$ SL; (ii) sjenaža lucerne uz dodatak $5 \mathrm{~g}$ sirutke $\mathrm{kg}^{-1}$ tjelesne mase kastriranih ovnova (SL5) i (iii) sjenaža lucerne uz dodatak $10 \mathrm{~g}$ sirutke $\mathrm{kg}^{-1}$ tjelesne mase kastriranih ovnova (SL10).

Dodatak sirutke u prahu SL smanjio je udio octene kiseline u buragu kastriranih ovnova $(\mathrm{P}<0,001)$, te povećao udio propionske $(\mathrm{P}<0,001)$ i mliječne kiseline $(\mathrm{P}<0,001)$. Kod tretmana SL5 i SL10 je utvrđen viši udio $(\mathrm{P}<0,01)$ izomaslačne kiseline u usporedbi s tretmanom SL. Kod tretmana SL10 je utvrđen viši udio izovalerijanske kiseline u usporedbi s tretmanom SL i SL5 $(\mathrm{P}<0,001)$.

Zaključeno je da dodatak sirutke u prahu obroku baziranom na sjenaži lucerne smanjuje udio octene kiseline, a povećava udio propionske i maslačne kiseline u buragu kastriranih ovnova.
\end{abstract}

Ključne riječi: sjenaža lucerne, sirutka u prahu, masne kiseline, burag

\section{Uvod}

U buragu preživača različite vrste mikroorganizama fermentiraju krmiva u spojeve prvenstveno dostupne mikrobima buraga i životinji. Ugljikohidrati fermentiraju do hlapivih masnih kiselina (HMK), koje životinji daju energiju (Russell i sur., 1992.). Proteini se razgrađuju do amonijskog N koji se ugrađuje u mikrobne proteine ako obrok sadrži dovoljno energije (Ceconi i sur., 2015). Ako obrok ne sadrži dovoljno energije, N se izlučuje iz organizma i ostaje neiskorišten za životinju i za mikrobe buraga (Storm i sur., 1983).

Prema ranijim istraživanjima, bakterije koje razgrađuju vlakna proizvode octenu kiselinu, a bakterije koje razgrađuju škrob proizvode propionsku kiselinu (Blaxter, 1962). Osnovne HMK u buragu su octena, propionska, maslačna, izomaslačna, izovalerijska i valerijska kiselina (Bergman, 1990), te druge kiseline koje su zastupljene u malim koncentracijama (Welkie i sur., 2010). Koncentracija i intenzitet proizvodnje pojedinih kiselina u buragu je indikator aktivnosti mikroorganizama buraga (Ngwa i sur., 2003). Niska učinkovitost fermentacije rezultira niskim sadržajem HMK u buragu životinja (Wang i Zhang, 2020).

Marina Vranić, Krešimir Bošnjak, corresponding autor: e-mail: kbosnjak@agr.hr Sveučilište u Zagrebu Agronomski fakultet, Zavod za specijalnu proizvodnju bilja, Svetošimunska cesta 25, 10000 Zagreb, Hrvatska,

Tomislav Mašek, Sveučilište u Zagrebu Veterinarski fakultet, Zavod za prehranu i dietetiku životinja, Heinzelova 55, 10000 Zagreb, Hrvatska

Katarina Lovrić, Mateo Papac, student/ica na Sveučilištu u Zagrebu Agronomski fakultet, Svetošimunska cesta 25, 10000 Zagreb, Hrvatska

Krešimir Krapinec, Sveučilište u Zagrebu Šumarski fakultet, Zavod za zaštitu šuma i lovno gospodarenje, Svetošimunska 25, 10000 Zagreb, Hrvatska

Goran Kiš, Sveučilištu u Zagrebu Agronomski fakultet, Zavod za hranidbu životinja, Svetošimunska cesta 25, 10000 Zagreb, Hrvatska 
Na koncentraciju kiselina u buragu utječe vrsta krme s kojom je povezana vrsta i broj bakterija (Hackmann i Firkins, 2015; Alstrup i sur., 2016.) kao i razina hranidbe životinja (Firkins i sur., 1986.; Robinson i sur., 1986.; Bergman, 1990). Zhang i sur. (2017) navode da omjer voluminozne krme i koncentrata u obroku ne utječe na ukupnu koncentraciju HMK u buragu nego na omjer octene, maslačne i propionske kiseline.

$\mathrm{S}$ porastom udjela voluminoznih krmiva u obroku, raste udio octene kiseline i $\mathrm{pH}$ buraga, a smanjuje se udio propionske kiseline (Hristov i sur., 2010). Udio octene kiseline u buragu bi, u odnosu na druge kiseline, trebao iznositi minimalno 75\%, a $\mathrm{pH}$ buraga više od 5,7 da se prevenira razvoj akutne acidoze buraga (Mc Donald i sur., 1996). Apsorpcija HMK u buragu je pasivan proces (Ash i Dobson, 1963.) ovisan o kontrakcijama buraga koje su intenzivnije kod hranidbe voluminoznom krmom što značajno povećava $\mathrm{pH}$ vrijednost sadržaja buraga $\mathrm{u}$ usporedbi s hranidbom obrocima bogatim koncentriranim krmivima (Hristov i sur., 2010).

Koncentrirana krmiva se dodaju voluminoznim krmivima radi zadovoljenja energetskih potreba životinja, bolje iskoristivosti obroka, veće ad libitum konzumacije i in vivo probavljivosti (Vranić i sur., 2008, 2011, 2013), a prema tome i veće proizvodnosti životinja. Sirutka je nus proizvod u proizvodnji sira. Kao izvor energije u obroku bi mogla zamijeniti dio žitarica i time povećati iskorištenje neproteinskog dušika od strane mikroba buraga (Schingoethe, 1976). Dodatak malih količina sirutke (2\% od ukupne količine konzumirane ST) travnoj ili kukuruznoj silaži povećava probavljivost glavnih komponenti obroka (Schingoethe, 1976). Gubitci amonijskog dušika se smanjuju, obrok je palatabilniji, a proizvodnost životinja veća (Schingoethe, 1976).

Hipoteza istraživanja je da će dodatak sirutke u prahu sjenaži lucerne smanjiti udio octene a povećati udio propionske i maslačne kiseline u buragu kastriranih ovnova. Cilj rada bio je utvrditi utjecaj dodatka 5 i 10 grama sirutke u prahu $\mathrm{kg}^{-1}$ tjelesne mase kastriranih ovnova sjenaži lucerne na udio masnih kiselina u buragu kastriranih ovnova.

\section{Materijali i metode rada}

Sjenaža lucerne

Lucerna je pokošena u fenološkoj fazi početka cvatnje oko $30 \%$ biljaka na pokušalištu Maksimir Agronomskog fakulteta Sveučilišta u Zagrebu. Košena je rotacionom kosilicom s kondicionerom. Pokošena biljna masa je na tlu provenuta tijekom 24 sata na 400-500 g ST kg-1 svježe mase, nakon čega je balirana u valjkaste bale promjera $125 \mathrm{~cm}$ i ovijena sa $4-6$ slojeva plastične folije. Valjkaste bale lucerne ovijene plastičnom folijom su transportirane u Centar za travnjaštvo gdje su ostavljene fermentirati 48 dana prije početka hranidbe. Prije svakog od ukupno 3 perioda pokusa, sjenaža lucerne je strojno sjeckana na $\mathrm{cca} 6 \mathrm{~cm}$ duljine, zbijana u plastične vreće koje su dobro zatvorene i zalijepljene plastičnom trakom te uskladištene u hladnoj komori na temperaturi od $4^{\circ} \mathrm{C}$ do hranidbe. 


\section{Sirutka u prahu}

Sirutka u prahu (pasterizirana slatka obrana sirutka) za potrebe istraživanja nabavljena je od tvrtke Dukat d.d., M. Čavića 9. 10000 Zagreb u pakiranjima od 25 kg.

\section{Hranidbeni tretmani}

Istraživan je utjecaj tri hranidbena tretmana na udio masnih kiselina u buragu kastriranih ovnova; (i) sjenaža lucerne $100 \%$ (SL); (ii) sjenaža lucerne uz dodatak $5 \mathrm{~g}$ sirutke $\mathrm{kg}^{-1}$ tjelesne mase kastriranih ovnova (SL5) i (iii) sjenaža lucerne uz dodatak $10 \mathrm{~g}$ sirutke $\mathrm{kg}^{-1}$ tjelesne mase kastriranih ovnova (SL10).

\section{Hranidba životinja}

Dnevna količina hrane je podijeljena $u$ dva jednaka obroka. Životinje su hranjene $2 \mathrm{x}$ dnevno (ujutro u 9,00 sati i poslije podne u 16,00 sati).

\section{Pokusne životinje}

U pokusu su korištena 3 kastrirana ovna tjelesne mase 30 - $35 \mathrm{~kg}$. Prije početka pokusa utvrđeno je da su životinje zdrave, pregledani su papci, životinje su ošišane, a posebno je odstranjena vuna oko repnog dijela, izvršeno je tretiranje protiv internih i eksternih parazita.

\section{Smještaj pokusnih životinja}

Za potrebe provedbe pokusa korištene su dvije pokusne prostorije dimenzija $11 \times 4.5 \mathrm{~m}$. Jedna je prostorija korištena za fazu adaptacije na hranidbeni tretman, opremljena individualnim boksevima za držanje životinja, dimenzija $1.5 \times 2.2 \mathrm{~m}$, individualnim hranilicama i pojilicama. Kao stelja je korištena piljevina.

U drugoj prostoriji su se nalazili individualni kavezi na kotačima dimenzija 136 x 53 x $148.5 \mathrm{~cm}$. Svaki od tih kaveza je na prednjoj strani opremljen hranilicom te pojilicom.

\section{Trajanje istraživanja}

Svaki od 3 hranidbena perioda pokusa se sastojao od 3 faze: (i) 10 dana adaptacija na hranu; (ii) 4 dana adaptacija na kaveze i (iii) 7 dana praćenje ad libitum konzumacije hrane. Obzirom da je svaki od 3 pokusna perioda trajao po 21 dan, pokus je sveukupno trajao 63 dana.

\section{Tjelesna masa pokusnih životinja}

Tjelesna masa životinja utvrđivana je vaganjem životinja prije početka svakog od 3 perioda pokusa korištenjem elektronske vage (TRU-TEST Ltd, Model 703B).

\section{Uzimanje uzoraka ruminalnog soka}

Uzorci ruminalnog soka (60 ml po životinji) uzimani su zadnji dan svakog hranidbenog perioda istraživanja ujutro u 9,00 sati neposredno prije hranidbe. Pomoću mekane gumene cijevi unutarnjeg promjera $18 \mathrm{~mm}$ je kroz usta životinje isisavan ruminalni sok u termos bocu 
zagrijanu na $39^{\circ} \mathrm{C}$ i napunjenu s $\mathrm{CO}_{2}$ plinom. Neposredno nakon uzimanja, ruminalni sok je procijeđen kroz 3 sloja gaze i raspoređen u staklene epruvete zapremine $80 \mathrm{ml}$. Epruvete su zatvorene originalnim zatvaračem na navoj, i uronjene u tekući dušik na temperaturu od $-160^{\circ} \mathrm{C}$. Konzerviran ruminalni sok je uskladišten na temperaturi od $-20^{\circ} \mathrm{C}$ do provedbe analiza na sadržaj masnih kiselina u laboratoriju.

\section{Kemijske analize}

Uzorci hrane su analizirani na sadržaj suhe tvari (ST). Dostavna vlaga $\left(\mathrm{g} \mathrm{kg}^{-1}\right.$ svježeg uzorka) je utvrđena sušenjem uzoraka u sušioniku s ventilatorom tvrtke ELE International na temperaturi od $60^{\circ} \mathrm{C}$ do konstantne mase uzoraka. Osušeni uzorci su samljeveni na veličinu čestica od $1 \mathrm{~mm}$ korištenjem mlina čekićara tvrtke Christy (Model 11), te tako pripremljeni za analiziranje u kemijskom laboratoriju.

Sadržaj organske tvari (OT) $\left(\mathrm{g} \mathrm{kg}^{-1} \mathrm{ST}\right)$ uzoraka je utvrđen spaljivanjem cca 5 grama uzorka u mikrovalnoj peći za spaljivanje uzoraka (ISO 5984). Sadržaj dušika je utvrđen metodom po Kjeldahl metodi (ISO 5983) korištenjem jedinice za razaranje te automatske jedinice za destilaciju/titraciju uzoraka tvrtke Gerhardt. Dobivena količina dušika se pomnoži s faktorom 6,25 i preračuna na sadržaj sirovih proteina $\left(\mathrm{g} \mathrm{kg}^{-1} \mathrm{ST}\right) \mathrm{u}$ uzorku.

Vrijednost pH je određivana u ekstraktu dobivenom od cca 10 grama svježe silaže i $100 \mathrm{ml}$ destilirane vode korištenjem $\mathrm{pH}$ metra $315 \mathrm{i}$ tvrtke WTW. Sadržaj neutralnih vlakana (NDV) i kiselih vlakana (KDV) je utvrđen prema metodi Van Soest i sur. (1991) kuhanjem uzoraka u neutralnom i kiselom detergentu (Ancom Fiber Analyser).

Mliječna i hlapive masne kiseline (octena, maslačna) u sjenaži lucerne utvrđene su metodom po Fliege-u kako je opisao Balzer (1961). Amonijski dušik (NH3-N g/kg ukupnog dušika) je utvrđen metodom po Bremner-u i Keeney-u (1965).

Sadržaj masnih kiselina u buražnom soku kastriranih ovnova je utvrđen na Zavodu za prehranu i dietetiku životinja Sveučilišta u Zagrebu Veterinarskog fakulteta primjenom metode plinske kromatrografije (Scortichini i sur., 2020). Spojevi u ovom postupku separacije i analize spojeva isparavaju bez razgradnje odnosno termički su stabilne. Uzorak se injektira u instrument i isparava u peći, odlazi do kolone gdje se kondenziraju i dijele različite komponente prema relativnom vremenu zadržavanja na stacionarnoj fazi (Scortichini i sur., 2020).

\section{Statistička obrada rezultata istraživanja}

Rezultati istraživanja obrađeni su u SAS programskom paketu, korištenjem MIXED procedure (SAS, 1999.).

Korišten je model: $\mathrm{Yij}=\mu+\mathrm{Ti}+\mathrm{Pj}+$ eij, gdje je $\mathrm{Y}=$ model, $\mu=$ srednja vrijednost, $\mathrm{T}=$ tretman, $\mathrm{P}=$ period, $\mathrm{e}=\mathrm{eksperimentalna} \mathrm{greška,} \mathrm{I}=$ broj tretmana, $\mathrm{j}=$ broj perioda. 


\section{Rezultati i rasprava rezultata istră̌ivanja}

Kemijski sastav sjenaže lucerne je prikazan u tablici 1.

Tablica 1. Kemijski sastav sjenaže lucerne ( $\mathrm{u} \mathrm{k} \mathrm{kg}^{-1} \mathrm{ST}$ ako nije drugačije navedeno) Table 1 Chemical composition of alfalfa haylage (ikn $\mathrm{g} \mathrm{kg}^{-1} \mathrm{DM}$ if not othervise stated)

\begin{tabular}{lcccc}
\hline $\begin{array}{c}\text { Kemijski parametar } \\
\text { Chemical parameter }\end{array}$ & $\begin{array}{c}\text { Srednja vrijednost } \\
\text { Mean value }\end{array}$ & Min & Max & CV (\%) \\
\hline ST/DM $\left(\mathrm{g} \mathrm{kg}^{-1}\right.$ svježeg uzorka/fresh sample) & 534,7 & 512,0 & 578,5 & 5,04 \\
\hline $\mathrm{OT} / \mathrm{OM}$ & 916,5 & 910,9 & 927,1 & 0,62 \\
\hline $\mathrm{SP} / \mathrm{CP}$ & 171,4 & 148,2 & 191,2 & 8,38 \\
\hline $\mathrm{NDV} / \mathrm{NDF}$ & 459,3 & 368,9 & 505,3 & 10,47 \\
\hline KDV/ADF & 378,5 & 300,6 & 442,9 & 12,37 \\
\hline Karakteristike fermentacije/Fermentation Characteristics & & & \\
\hline Mliječna kiselina/Lactic Acid & 16,9 & 11,4 & 27,1 & 35,7 \\
\hline Octena kiselina/Acetic Acid & 14,5 & 11,7 & 30,7 & 86,5 \\
\hline Maslačna kiselina/Butyric Acid & 0,0 & 0,0 & 0,0 & 0,0 \\
\hline pH & 5,0 & 4,9 & 5,1 & 1,46 \\
\hline $\mathrm{NH}_{3}-\mathrm{N}$ (g N kg ${ }^{-1}$ ukupnog/total N) & 79,8 & 76,0 & 83,5 & 3,8 \\
\hline
\end{tabular}

ST, suha tvar; OT, organska tvar; SP, sirovi proteini; NDV, neutralna detergent vlakna; KDV, kisela detergent vlakna; Min, minimalna vrijednost; Max, maksimalna vrijednost, $\mathrm{CV}$, koeficijent varijacije.

DM, dry matter; CP, crude protein; OM, organic matter; NDF, neutral detergent fibre; ADF, acid detergent fibre; Min - minimal value; Max - maximal value; $\mathrm{CV}$ - coeficient of variation.

Sadržaj NDV, KDV i SP korištene SL (tablica 1) se uklapa u tipične vrijednosti sadržaja tih parametara u sjenaži lucerne (NRC, 2001). Prosječan sadržaj SP SL od $171.4 \mathrm{~g} \mathrm{~kg}^{-1} \mathrm{ST}$ je nešto niži od prosječnog sadržaja SP (180 $\left.\mathrm{g} \mathrm{SP} \mathrm{kg}^{-1} \mathrm{ST}\right)$ usjeva lucerne košenog u početku cvatnje (Ball i sur., 2002.), ali je unutar raspona sadržaja SP travnih silaža od 150-175 g SP kg-1 ST (Chamberlain and Wilkinson, 1996).

Sadržaj ST SL od 534,7 $\mathrm{g} \mathrm{kg}^{-1}$ svježeg uzorka je bio je u višem rasponu sadržaja ST sjenaže lucerne korištene u ranijim istraživanjima (420-541 $\mathrm{g} \mathrm{kg}^{-1}$ svježeg uzorka) (Jones i sur., 1992; Kung i sur., 2003; Filya i sur., 2007). Lucerna nije pogodna za siliranje radi niskog sadržaja ugljikohuidrata topivih u vodi i visokog pufernog kapaciteta (McAllister i sur., 1998). Visoki sadržaj ST je vjerojatno pomogao očuvanju hranidbene vrijednosti fermentirane lucerne jer visoki sadržaj ST usjeva za siliranje može smanjiti gubitke hranjivih tvari siliranjem (Jones i sur., 1992). Viša pH vrijednost SL od preporučene (4,5-5) za fermentiranu biljnu masu trava i mahunarki (Chamberlain i Wilkinson, 1996) i niska koncentracija mliječne i octene kiseline su rezultat ograničene fermentacije radi većeg sadržaja ST lucerne prije siliranja (Stallings i sur., 1981), u usporedbi s ranijim istraživanjima u kojima je korištena silirana lucerna (Kung i sur., 2003; Filya i sur., 2007).

Viši udio $\mathrm{NH}_{3}-\mathrm{N}$ od utvrđenog u poželjnim travnim silažama (do $50 \mathrm{~g} \mathrm{NH}_{3}-\mathrm{N} \mathrm{kg}^{-1}$ ukup$\operatorname{nog} \mathrm{N}$ ) je u skladu s višim udjelom ST, a time i produljenom proteolizom radi težeg postizanja anaerobnih uvjeta u silosu (Jones i sur., 1992; Kung i sur., 2003).

U tablici 2. nalazi se prikaz kemijskog sastava sirutke u prahu. 
Tablica 2. Kemijski sastav sirutke u prahu (prema deklaraciji proizvođača)

Table 2 Chemical composition od dry whey (according to producer declaration)

\begin{tabular}{lcc}
\hline \multicolumn{1}{c}{$\begin{array}{c}\text { Parametar } \\
\text { Parameter }\end{array}$} & $\begin{array}{c}\text { Prosječna vrijednost } \\
\text { Mean value }\end{array}$ & $\begin{array}{c}\text { Jedinica mjere } \\
\text { Unit }\end{array}$ \\
\hline Suha tvar / Dry matter & 950 & $\mathrm{~g} \mathrm{~kg}^{-1}$ \\
\hline $\begin{array}{l}\text { Energetska vriježeg uzorka/fresh sample } \\
\text { Energy value }\end{array}$ & 1446,5 & $\mathrm{~kJ}$ \\
\hline Bjelančevine / Protein & 340,5 & $\mathrm{Kcal}$ \\
\hline $\begin{array}{l}\text { Ugljikohidrati } \\
\text { Carbohydrates }\end{array}$ & 90 & $\mathrm{~g} \mathrm{~kg}^{-1} \mathrm{ST} / \mathrm{DM}$ \\
\hline Masti / Fat & 75 & $\mathrm{~g} \mathrm{~kg}^{-1} \mathrm{ST} / \mathrm{DM}$ \\
\hline Laktoza / Lactose & 0,75 & $\mathrm{~g} \mathrm{~kg}^{-1} \mathrm{ST} / \mathrm{DM}$ \\
\hline
\end{tabular}

ST, suha tvar; DM, dry matter

Kemijski sastav sirutke u prahu varira ovisno o vrsti sira čiji je nus proizvod, metodi konzerviranja, te porijeklu mlijeka. Sirutka u prahu u ST sadrži većim dijelom laktozu što je i vidljivo iz tablice 2 . U ovom istraživanju je sadržaj laktoze prikazan prema deklaraciji proizvođača i uklapa se u uobičajen sadržaj laktoze u osušenoj slatkoj sirutki od $750 \mathrm{~g} \mathrm{~kg}^{-1} \mathrm{ST}$ (Duvnjak i Kosarić, 1983), a sadržaj SP je niži od ranije navedenog za slatku sirutku u prahu od $131 \mathrm{~g} \mathrm{~kg}^{-1}$ ST (Duvnjak i Kosarić, 1983).

Udio masnih kiselina u buragu pokusnih životinja je prikazan u tablici 3.

Tablica 3. Utjecaj hranidbenog tretmana na udio masnih kiselina u buragu

Table 3 The effect of feeding treatment on the proportion of fatty acids in rumen

\begin{tabular}{lcccccc}
\hline $\begin{array}{c}\text { Hranidbeni } \\
\text { tretman/ } \\
\text { feeding } \\
\text { treatment }\end{array}$ & $\begin{array}{c}\text { Octena/ } \\
\text { Acetic }\end{array}$ & $\begin{array}{c}\text { Propionska/ } \\
\text { Propionic }\end{array}$ & $\begin{array}{c}\text { Izomaslačna/ } \\
\text { Isobutyric }\end{array}$ & $\begin{array}{c}\text { Maslačna/ } \\
\text { Butyric }\end{array}$ & $\begin{array}{c}\text { Izovalerijanska// } \\
\text { Isovalerian }\end{array}$ & $\begin{array}{c}\text { Valerijanska/ } \\
\text { Valerian }\end{array}$ \\
\hline SL & $75,2^{\mathrm{a}}$ & $15,8^{\mathrm{a}}$ & $0,8^{\mathrm{a}}$ & $6,2^{\mathrm{a}}$ & $0,72^{\mathrm{a}}$ & 1,15 \\
\hline $\mathrm{SL5}$ & $73,1^{\mathrm{b}}$ & $16,8^{\mathrm{b}}$ & $1,0^{\mathrm{b}}$ & $7,3^{\mathrm{b}}$ & $0,66^{\mathrm{a}}$ & 1,14 \\
\hline SL10 & $69,9^{\mathrm{c}}$ & $17,9^{\mathrm{c}}$ & $0,9^{\mathrm{b}}$ & $8,9^{\mathrm{c}}$ & $1,0^{\mathrm{b}}$ & 1,15 \\
\hline SEM & 0,38 & 0,16 & 0,03 & 0,16 & 0,03 & 0,04 \\
\hline $\mathrm{P}$ & $* * *$ & $* * *$ & $* *$ & $* * *$ & $* * *$ & N.S. \\
\hline
\end{tabular}

SL, hranidba sjenažom lucerne 100\%; SL5, hranidba sjenažom lucerne uz dodatak 5 g osušene sirutke kg-1 tjelesne mase kastriranih ovnova; SL10, hranidba sjenažom lucerne uz dodatak 10 g osušene sirutke kg-1 tjelesne mase kastriranih ovnova; SEM, standardna greška srednje vrijednosti; Vrijednosti u svakoj koloni označene različitim slovima se statistički značajno razlikuju, $* * \mathrm{P}<0,01 ; * * * \mathrm{P}<0,001$; NS, nije statistički značajna razlika $(\mathrm{P}>0,05)$.

SL, alfalfa haylage $100 \%$; SL5, alfalfa haylage supplemeted with $5 \mathrm{~g}$ of dry whey $\mathrm{kg}^{-1}$ body weight of wether sheep; SL10, alfalfa haylage supplemeted with $10 \mathrm{~g}$ of dry whey $\mathrm{kg}^{-1}$ body weight of wether sheep; S.E.M., standard error of the mean; Values in each column marked with different letter differ significantly, $* * \mathrm{P}<0.01, * * * \mathrm{P}<0.001$; NS, not significant $(\mathrm{P}>0.05)$. 
Utvrđeno je da na koncentraciju kiselina u buragu utječe vrsta krme s kojom je povezana vrsta i broj bakterija (Hackmann i Firkins, 2015; Alstrup i sur., 2016) kao i razina hranidbe životinja (Firkins i sur., 1986.; Robinson i sur., 1986.; Bergman, 1990). Dodatak sirutke u prahu SL je smanjio sadržaj octene kiseline u buragu kastriranih ovnova $(\mathrm{P}<0,001)$, te povećao sadržaj propionske kiseline $(\mathrm{P}<0,001)$ i sadržaj mliječne kiseline $(\mathrm{P}<0,001)$. Kod tretmana SL5 i SL10 je utvrđen viši udio $(\mathrm{P}<0,01)$ izomaslačne kiseline u usporedbi s tretmanom SL. Kod tretmana SL10 je utvrđen viši udio izovalerijanske kiseline u usporedbi s tretmanom SL i SL5 (P<0,001). U ranijim istraživanjima je također utvrđen visoki udio octene, u odnosu na druge kiseline buražnog soka, kod hranidbe ovaca slamom (82,85 \%) ili lucernom (82,16\%) (Ngwa i sur., 2003) kao i kod hranidbe visokim udjelom voluminozne krme (79,84\%) (Wang i sur., 2003), a nešto niži kod hranidbe visokom razinom koncentrata u obroku $(69,24 \%)$ (Wang i Zhang, 2020). Rezultati su u suglasju s ranijim istraživanjima da s porastom udjela voluminoznih krmiva u obroku, raste udio octene kiseline i pH buraga, a smanjuje se udio propionske kiseline (Hristov i sur., 2010). Udio octene kiseline u buragu bi, u odnosu na druge kiseline, trebao iznositi minimalno 75\% (Mc Donald i sur., 1996) što je utvrđeno ovim istraživanjem za tretman SL $(75,2 \%)$ dok je kod tretmana SL5 i SL10 utvrđen nešto niži udio octene kiseline od preporučenog za osiguranje normalne funkcije i zdravlja gastrointestinalnog trakta preživača (Mc Donald i sur., 1996). Udio octene kiseline kod tretmana SL10 $(69,9 \%)$ se može usporediti s udjelom octene kiseline $(69,24 \%)$ u buražnom soku kod hranidbe goveda obrokom bogatim koncentratom (Wang i Zhang, 2020). Sadržaj propionske kiseline u ovom istraživanju je viši od 11,13\% i 11,9\% koji je utvrđen kod hranidbe ovaca slamom ili lucernom (Ngwa i sur., 2003), odnosno niži u odnosu na 19,32\% i 23,87\% kod hranidbe goveda obrokom bogatim na voluminoznoj krmi (Wang i Zhang, 2020).

Utvrđen udio izomaslačne i valerijske masne kiseline u ruminalnom soku je viši, a izovalerijske kiseline niži u odnosu na rezultate istraživanja udjela masnih kiselina u ruminalnom soku kod hranidbe ovaca slamom i lucernom (Ngwa i sur., 2003)

Sadržaj pojedinih HMK u ruminalnom soku nije konstantan tijekom dana. Ruminalni sok prije hranidbe ima niži sadržaj HMK i veću $\mathrm{pH}$ vrijednost u usporedbi s ruminalnim sokom uzetim za analizu neposredno nakon hranidbe (Welkie i sur., 2010). Stoga i vrijeme uzorkovanja ruminalnog soka ima značajan utjecaj na sadržaj i omjer masnih kiselina (Welkie i sur., 2010). Ruminalni sok, za potrebe ovog istraživanja, je uzet neposredno prije jutarnje hranidbe, a dobivene vrijednosti za udio octene kiseline $(75,2 \%)$ bile su između vrijednosti udjela octene kiseline u ruminalnom soku prije hranidbe voluminoznim obrokom $(79,84 \%)$ i prije hranidbe obrokom višeg udjela koncentrata $(69,24 \%)$ (Wang i Zhang, 2020).

\section{Zaključak}

Zaključeno je da dodatak sirutke u prahu obroku baziranom na sjenaži lucerne smanjuje udio octene kiseline, a povećava udio propionske i maslačne kiseline u buragu kastriranih ovnova. 


\section{LITERATURA}

1. Alstrup, L., Søegaard K., Weisbjerg M.R. (2016). Effects of maturity and harvest season of grass-clover silage and of forage-to-concentrate ratio on milk production of dairy cows. Journal of Dairy Science, 99: 328-340.

2. Ash R.W., Dobson A. (1963). The effect of absorption on the acidity of rumen contents. Journal of Physiology, 169: 39-61.

3. Blaxter, K.L. (1962). The energy metabolism of ruminants. Digestive physiology and metabolism in ruminants: proceedings of the 5th. Springer: Springfield, UK.

4. Bergman E.N. (1990). Energy contributions of volatile fatty acids from gastrointestinal tract in various species. Physiological Review, 70: 567-590.

5. Ball D.M., Hoveland C.S., Lacefield G.D. (2002). Southern Forages. Third edition. Published by the Potash and Phosphate Institute (PPI), Georgia, USA

6. Balzer I. (1961). Analitičke metode određivanja kvalitete silaže. Krmiva, 2: 41-44.

7. Bremner, J.M.; Keeney, D.R. (1965.): Steam distilled methods for determination of ammonium, nitrate and nitrite. Analytical Chemical Acta, 32, 485-497.

8. Chamberlain A.T., Wilkinson J.M. (1996). Feeding the Dairy Cow. Chalcombe Publications, PainShall, Ln2 $3 \mathrm{LT}, \mathrm{UK}$

9. Ceconi I., Ruiz-Moreno M., DiLorenzo N., DiCostanzo A., Crawford G. I. (2015). Effect of urea inclusion in diets containing corn dried distillers grains on feedlot cattle performance, carcass characteristics, ruminal fermentation, total tract digestibility, and purine derivatives-to-creatinine index. Journal of Animal Science, 93: 357-369.

10. Duvnjak, Z., Kosarić, N. (1983). Sirutka i njeno korištenje u prehrambenoj i farmaceutskoj industriji. MIjekarstvo 33, 2:45-61.

11. Firkins J.L., Berger L.L., Merchen N.R., Fahez Jr. G.C. (1986). Effects of forage particle size, level of feed intake and supplemental protein degradability on microbial protein synthesis and site of nutrient digestion in steers. Journal of Animal Science, 62:1081-1094.

12. Filya I., Muck R. E., Contreras-Govea F. E. (2007). Inoculant effects on alfalfa silage: fermentation products and nutritive value. Journal of Dairy Science, 90: 5108-5114.

13. Hackmann T.J., Firkins J.L. (2015). Maximizing efficiency of rumen microbial protein production. Frontiers in Microbiology, 6: 465-471.

14. Hristov A.N., Zaman S., Schneider C. (2010). Effect of dietary concentrate on rumen fermentation, digestibility, and nitrogen losses in dairy cows. Journal of Dairy Science, 93: 4211-4222.

15. ISO (International Standard Organization) (1979). Animal Feedstuffs, ISO 5983., ISO 5984, International Organization for Standardization, Geneva, Switzerland.

16. Jones B. A., Satter L. D., Muck, R. E. (1992). Influence of bacterial inoculant and substrate addition to lucerne ensiled at different dry matter contents. Grass and Forage Science, 47:19-27.

17. Kung Jr. L., Taylor C. C., Lynch M. P., Neylon J.M. (2003). The effect of treating alfalfa with Lactobacillus buchneri 40788 on silage fermentation, aerobic stability, and nutritive value for lactating dairy cows. Journal of Dairy Science, 86: 336-343.

18. McAllister T.A., Feniuk R., Mir Z., Mir P., Selinger L. B., Cheng K.J. (1998). Inoculants for alfalfa silage: Effects on aerobic stability, digestibility and the growth performance of feedlot steers. Livestock Production Science, 53:171-181. 
19. McDonald P., Edwards R.A., Greenhalgh J.F.D. (1996). Animal nutrition, $5^{\text {th }}$. Edition Longman Groups, UK.

20. Ngwa A., Nsahlai I., lji P. (2003). Effect of feeding legume pods or alfalfa in combination with poor quality grass straw on microbial enzyme activity and production of VFA in the rumen of South African Merino sheep. Small Ruminant Research, 48(2): 83-94.

21. National Research Council (NRC) (2001). Nutrient Requirements of Dairy Cattle. Seventh Revised Edition 2001. National Academic Press, Washington, D.C., 381 pp.

22. Robinson P.H., Taminga S., Van Vuuren A.M. (1986). Influence of declining level of feed intake and varying the proportion of starch in the concentrate on rumen fermentation in dairy cows. Livestock Production Science 15: 173-189.

23. Russell J.B., O'Connor J.D., Fox D.G., Van Soest P.J., Sniffen C.J. (1992). A net carbohydrate and protein system for evaluating cattle diets: I. ruminal fermentation. Journal of Animal Science, 70: 3551-3561.

24. Schingoethe D.J. (1976). Whey utilization in animal feeding: a summary and evaluation. Journal of Dairy Science, 59(3): 556-570.

25. Schingoethe D.J., Beardsley G.L. (1975). Feeding value of corn silage containing added urea and dried whey. Journal of Dairy Science, 58(2): 196- 201.

26. SAS (1999). SAS ${ }^{\circledR}$ Software, SAS Institute Inc., Cary, North Carolina, USA.

27. Scortichini S., Boarelli M.C., Castello M., Chiavarini F., Gabrielli S., Marcantoni E., Fiorini D. (2020). Development and application of a solid-phase microextraction gas cromatography mass spectrometry method for analysing volatile organic compounds produced during cooking. Journal of mass spectrometry, 55, 11: 1-13.

28. Stallings C.C., Townes R., Jesse B.W., Thomas J.W. (1981). Changes in alfalfa haylage during wilting and ensiling with and without additives. Journal of Animal Science, 53:765-773.

29. Storm E., Ørskov E.R., Smart R. (1983). The nutritive value of rumen micro-organisms in ruminants. British Journal of Nutrition, 50, 02: 471.

30. Van Soest P.J., Robertson J.B., Lewis B.A. (1991). Method for dietary fiber, neutral detergent fiber and nonstarch polysaccharides in relation to animal nutrition. Journal of Dairy Science, 74: 3583-3597.

31. Vranić, M., Knežević M., Bošnjak K., Leto J., Perčulija G., Matić I. (2008). Effects of replacing grass silage harvested at two maturity stages with maize silage in the ration upon the intake, digestibility and $\mathrm{N}$ retention in wether sheep. Livestock Science 114(1):84-92.

32. Vranić, M., Knežević M., Perčulija G., Bošnjak K., Leto J., Kutnjak H., Horg M. (2011). Fermented high moisture maize grain as supplement to alfalfa haylage is superior over unfermented dry maize grain in diet dry matter digestibility. Mljekarstvo 61(3):244-251.

33. Vranić, M., Bošnjak, K., Perčulija, G., Leto, J., Kutnjak, H., Pejić, K. (2013). The feeding value of the ration based on alfalfa haylage supplemented with high moisture corn in wether sheep. Acta Veterinaria (Beograd), 63, 4: 421-428.

34. Wang Z.L., Zhang L. (2020). Effects of High Forage/Concentrate Diet on Volatile Fatty Acid Production and the Microorganisms Involved in VFA Production in Cow Rumen. Animals, 10, 2: 223.

35. Welkie D.G., Stevenson D.M., Weimer P.J. (2010) ARISA analysis of ruminal bacterial community dynamics in lactating dairy cows during the feeding cycle. Anaerobe, 16: 94-100.

36. Zhang J., Shi H., Wang Y., Li S., Cao Z., Ji S., Zhang H. (2017). Effect of dietary forage to concentrate ratios on dynamic profile changes and interactions of ruminal microbiota and metabolites in Holstein heifers. Frontiers in Microbiology, 8: 2206-2214. 


\title{
THE EFFECT OF DRY WHEY SUPPLEMENTATION TO ALFALFA HAYLAGE ON THE PROPORTION OF RUMEN FATTY ACIDS IN WETHER SHEEP
}

\begin{abstract}
Summary
The objective of this study was to determine the effect of dry whey supplementation to alfalfa haylage (AH) on fatty acids concentration in the rumen of whether sheep.

Total of 3 feeding treatments were used in the study: (i) $100 \% \mathrm{AH}$; (ii) $\mathrm{AH}$ supplemeneted with of $5 \mathrm{~g}$ whey $\mathrm{kg}^{-1}$ body weight of wether sheep (AH5) and (iii) AH supplemeneted with $10 \mathrm{~g}$ whey $\mathrm{kg}^{-1}$ body weight of wether sheep (AH10).

The supplementation of whey to AH reduced the proportion of acetic acid in the rumen of wether sheep $(\mathrm{P}<0.001)$, and increased the proportion of propionic $(\mathrm{P}<0.001)$ and butyric acid $(\mathrm{P}<0.001)$. In the AH5 and AH10 treatments, a higher proportion $(\mathrm{P}<0.01)$ of isobutyric acid was found compared to the AH treatment. A higher proportion of isovaleric acid was determined in the AH10 treatment compared to the $\mathrm{AH}$ and $\mathrm{AH} 5$ treatment $(\mathrm{P}<0.001)$.

It was concluded that the supplementation of whey to alfalfa haylage reduces the proportion of acetic acid and increases the proportion of propionic and butyric acid in the rumen of wether sheep.
\end{abstract}

Key words: alfalfa haylage, whey, fatty acids, rumen 